\title{
A reestruturação produtiva universitária e suas consequências sobre a produção acadêmica
}

\author{
Bernardo Parodi Svartman ${ }^{a}$ \\ José Leon Crochík ${ }^{b}$ \\ Gustavo Martineli Massola ${ }^{a}$ \\ aUniversidade de São Paulo, Instituto de Psicologia, Departamento de Psicologia Social e do Trabalho. São Paulo, SP, Brasil \\ 'Universidade de São Paulo, Instituto de Psicologia, Departamento de Psicologia da Aprendizagem, \\ do Desenvolvimento e da Personalidade. São Paulo, SP, Brasil
}

As relações entre sistema produtivo e criação de conhecimento científico ganham relevância contemporaneamente no Brasil, quando as instâncias de administração universitária procuram intensificar o impacto comercial da atividade acadêmica na forma, por exemplo, de cursos, consultorias e patentes. Pode-se argumentar que tal estado de coisas já estivesse implícito na origem da ciência como instituição, mas sua configuração só ganhou plenitude nos Estados Unidos após o final da II Guerra, quando o sistema industrial, o sistema militar e o conjunto de instituições responsáveis pelo desenvolvimento científico e tecnológico naquele país, agora formando também um sistema, começaram a operar em conjunto, constituindo o que passou a ser conhecido como big science (Domingues, 2014) e compondo um aspecto significativo do quadro geopolítico que operou durante a Guerra Fria. Neste cenário, não há separação temporal entre a criação de conhecimento científico e sua aplicação tecnológica (Tassara, 2013), o que torna pouco pertinente a distinção entre ciência pura e aplicada - a própria criação de conhecimento se faz por encomenda do Estado, com finalidades político-militares e também industriais; a ciência aproxima-se da esfera da produção de mercadorias, e as ideias passam a ser vistas como produtos a serem comercializados -; chega ao fim a era da ciência acadêmica e da "idade da inocência" e tem início a era da ciência industrial (Domingues, 2014).

Conquanto tenha levado algumas décadas para que tal configuração fosse observada mais claramente no Brasil, ela vem se impondo rapidamente no cotidiano de trabalho de professores e pesquisadores, e é cada vez mais pertinente, do ponto de vista da crítica social do conhecimento, observar em conjunto as transformações que vêm ocorrendo na indústria e na universidade. Neste sentido, nas últimas décadas, houve mudança acentuada na organização do trabalho universitário, que pode, de pleno direito, ser caracterizada como uma reestruturação produtiva.

A expressão "reestruturação produtiva" consagrou-se na literatura sociológica como o termo que designa as recentes transformações da organização do trabalho, de seus aspectos técnicos e das formas de mobilização da mão de obra dentro e fora dos ambientes de trabalho, ocorridas a partir da década de 1970 nos países capitalistas (Harvey, 2010). Ainda que não tenham ocorrido de forma homogênea nos países centrais ou periféricos, essas transformações estão articuladas ao avanço das políticas neoliberais: a superação da crise de acumulação desse período e a reposição dos patamares anteriores de expansão do capital demandaram uma articulação entre políticas de desregulamentação dos direitos do trabalho, privatização do Estado, desmontagem do setor público estatal e novas formas de planejamento e execução das atividades de trabalho (Antunes, 2002), sem que o estado tenha abdicado de sua função do controle da população.

No interior dos ambientes de trabalho, com o apoio das novas tecnologias de informação e comunicação, buscou-se ampliar a racionalização do trabalho por meio da redução de estoques e do desperdício de tempo e materiais. Além disso, a estrutura produtiva deve ser capaz de se adaptar rapidamente às variações e exigências da demanda do consumo, ou seja, criar um sistema de produção just in time, implicando ajustes imediatos tanto em relação à produção das mercadorias quanto em relação à quantidade e à capacitação técnica dos trabalhadores. Fora dos ambientes de trabalho investiu-se contra formas de mediação estatal da relação capital-trabalho, por exemplo, contra políticas de seguridade social e o impedimento da terceirização da contratação de trabalhadores.

Uma das vertentes da política neoliberal consiste em apresentar os serviços públicos como uma máquina inchada e ineficiente, implicando custos problemáticos para o Estado, ideologia que defende a aplicação da racionalidade econômica para a organização e funcionamento desses mesmos serviços e a "abertura" e "desregulamentação" desses nichos de mercado. A noção de "Estado mínimo" representa apenas uma tentativa de encobrimento das novas relações entre o Estado e o capital, relações que se mostram efetivamente nas diversas formas contemporâneas de privatização da esfera pública. Como afirmou Francisco de Oliveira:

A privatização do público é uma falsa consciência de desnecessidade do público. Ela se objetiva pela chamada falência do Estado, pelo mecanismo da dívida pública interna onde as formas aparentes são as de que o privado, as burguesias emprestam ao Estado: logo, o Estado, nessa aparência, somente se sustenta como uma extensão do privado. $O$ processo real é o inverso: a riqueza pública, em forma de 
fundo, sustenta reprodutibilidade do valor da riqueza, do capital privado. Esta é a forma moderna de sustentação da crise do capital, pois anteriormente, como nos mostrou a Grande Depressão de trinta, assim como todas as grandes crises anteriores, o capital simplesmente desvalorizava. (Oliveira, 1999, p. 68)

O novo contexto econômico e político abriu as portas gradualmente para a reestruturação produtiva universitária desde a década 1980, e as mesmas transformações dos ambientes de trabalho passam a ser pensadas para a universidade, mas agora de forma explícita e acelerada. Como afirmou Jean Pierre Durand (2003), uma das principais conquistas da nova combinatória produtiva foi a "naturalização dos constrangimentos", uma vez que as metas e as exigências aparecem como perfeitamente aderidas à racionalidade do sistema produtivo, não mais mediatizadas por pessoas ou chefes. A necessidade de se manter o fluxo produtivo em funcionamento aparece como uma exigência natural à qual todos os trabalhadores precisam adaptar-se. Os grupos de trabalho (teamwork), divulgados como uma das principais inovações da organização do trabalho, no interior de um ambiente onde as metas são definidas de forma heterônoma, transformam-se num poderoso meio pelo qual os próprios trabalhadores passam a fiscalizar o rendimento de seus colegas, diminuindo a visibilidade do conflito com os centros de poder.

A interiorização dessa aceitação naturalizada difere de modo notável da relação social que o empregado podia manter anteriormente com a direção, pois agora a "polícia está no fluxo" e a direção, ela mesma, é subjugada pelo fluxo, reduzida a tarefas administrativas (antes que de comando) cujo objetivo essencial é de manter tensionado o fluxo.

(Durand, 2003, p. 148)

No caso universitário, os programas de pós-graduação correm o risco de serem assimilados à forma de uma "célula de trabalho" nesse molde, uma vez que o sistema de avaliação e imposição de metas é formulado de maneira heterônoma e a competição entre programas aparece como o ambiente natural que determina a manutenção do ritmo produtivo. As frustrações e tensões tendem a ser canalizadas para dentro do funcionamento dos grupos, nos quais surgem dinâmicas próprias de constrangimento e exclusão (surge a tentação de se dividir os programas entre professores produtivos e improdutivos), uma vez que o contexto mais amplo que determina a racionalidade produtiva naturaliza-se e torna-se invisível.

Outro aspecto importante da reestruturação produtiva que tende a ser assimilado no ambiente da universidade é a "sistematização da precariedade": começam a surgir propostas de formas de contratação que criam um grupo de trabalhadores estáveis e outro grupo precarizado, ou seja, trabalhadores terceirizados ou trabalhando em regimes de turno parcial. Surgem também propostas de que as avaliações periódicas de produtividade possam definir a manutenção ou alteração do regime de contratação dos professores. Este modelo de centro e periferia em relação ao regime de contratação acarreta poderosos efeitos psicossociais: enquanto o grupo de precarizados sacrifica-se para ingressar no grupo estável, os trabalhadores deste último grupo são sempre ameaçados de recair à periferia (Durand, 2003). Esta estratégia, que envolve uma forma precisa de avaliação do trabalho, revelou-se nos ambientes produtivos como uma técnica adequada para aumentar a produtividade e o controle sobre o trabalho, para aumentar a competição entre os trabalhadores, diminuir os laços de solidariedade e o papel dos sindicatos nos ambientes de trabalho.

Se o risco pretendia justificar o lucro do capitalista (Horkheimer \& Adorno, 1985), na sua ausência, só a sua pretensa necessidade o justifica: é necessário incentivar o consumo conspícuo, tal como o denomina Veblen (1983). Os monopólios e os oligopólios podem prescindir de seus empreendedores aventureiros e forçam todos a se adaptar às regras da racionalidade econômica. A educação e o acesso à publicação científica tendem a se adaptar a esse contexto: o ensino universitário privado consolida de forma crescente seus oligopólios, em alguns casos, associados ao capital financeiro; na universidade pública, seu objetivo de tornar a sua produção científica internacional, nos moldes dessa relação entre universidade e mercado, faz com que a reflexão sobre sua "função social" apareça aprisionada à apresentação dos resultados obtidos nos rankings internacionais, à sua comparação com universidades nas quais o modelo neoliberal está consolidado e à discussão de sua capacidade de inovação tecnológica ou produção de patentes. O sentido de autonomia universitária se reduz tal como a autonomia das diversas esferas sociais, outrora definidas como superestrutura social, à "autonomia" para geração e administração de receitas, por meio da produtividade científica. $\mathrm{Na}$ área da editoração das revistas acadêmicas também é possível notar a tendência à formação dos oligopólios, fenômeno que pode ser ilustrado pelo surgimento e fortalecimento de "organizações" que obtêm rendimentos crescentes vendendo o acesso aberto de seus produtos (os nossos artigos) segundo aquela mesma racionalidade.

Simmel (1896/2009) já havia demonstrado que o funcionamento e ampliação do livre mercado têm uma série de consequências psicossociais, como por exemplo, o fato de que quando tudo pode ser comparado com tudo por meio da racionalidade econômica, cada termo comparado perde sua especificidade, reduz-se ao que é comum a todos os termos, ou seja, a seus aspectos mais abstratos e quantitativos. Neste momento, a velocidade do fluxo passa a ser mais importante que qualquer imagem ou ideal de estabilidade e permanência, pois a produção de mercadorias exige o movimento em proporções cada vez maiores. O papel da memória e da história também se reduz, uma vez que o valor reduzido à sua dimensão econômica é imediato, e para que a troca possa se incrementar, qualquer resquício de valores do passado não assimiláveis a essa racionalidade 
devem ser eliminados, ainda que a história não deixe de exercer, mesmo imperceptivelmente, o seu papel, que é ideologicamente ignorado.

Estimula-se, na universidade, uma forma de produção adaptada às exigências imediatas, determinada tanto pela velocidade exigida da produção como em relação aos interesses sociais imediatos que são visados pelo conhecimento; cada vez mais a especificidade da escrita científica, que em princípio deveria adequar-se a seu objeto, encontra-se padronizada para que o fluxo de intercâmbio e de citações de artigos e a velocidade de publicação não sejam prejudicados; se o que é publicado merece ou não ser lido, não é posto em questão, desde que siga os critérios formais, inclusive para a revisão da literatura e para a descrição e discussão dos resultados; a estética minimalista entra em cena aqui: nada a mais deve ser posto no texto, a não ser o que é previamente disciplinado: a forma toma o lugar do conteúdo, tornando-se o próprio conteúdo a ser lido e avaliado; talvez se trate de "produção improdutiva", similar à que Marcuse (1981) enunciou como trabalho sem ocupação, que serve somente para justificar a mais-valia retirada do trabalho alheio:

Uma progressiva redução de mão-de-obra parece ser inevitável, e o sistema, para fazer face a essa eventualidade, tem de prover à criação de ocupações sem trabalho; tem de desenvolver necessidades que transcendem a economia de mercado e que podem até ser incompatíveis com ele. (Marcuse, 1981, p. 21)

Se a "produção improdutiva" se estabelece, as condições para uma verdadeira produção intelectual se deterioram. O tempo necessário para a reflexão diminui e é consideravelmente mal visto entre os próprios pesquisadores e professores, que aprisionados pelo fetiche da (falsa) produtividade se esforçam a atribuir valor ao que nem sempre o tem. Talvez a publicação pela publicação indique uma resposta inadequada ao problema da crise de relevância e do sentido social da produção científica atual, que ilusoriamente busca justificar-se como importante por meio do volume e quantidade de produção. Alguns dos dados que indicam esta tendência são os índices bibliométricos que avaliam citações apenas dos últimos cinco anos e o aumento das retratações de pesquisadores em relação ao material publicado (retratações que parecem com os recalls feitos constantemente em máquinas novas que tiveram um controle de qualidade insuficiente).

As exigências de profissionalização e internacionalização dos periódicos são racionais, uma vez que ninguém é contrário à possibilidade de que os autores tenham respostas rápidas no processo de submissão e que, caso o artigo seja aprovado, o tempo para publicação seja breve, assim com ninguém é contrário ao incremento do intercâmbio internacional do conhecimento produzido. As respostas imediatas são uma forma de respeitar as pessoas que submetem um manuscrito a ser publicado; a internacionalização é uma importante forma de ampliar o cosmopolitismo. $\mathrm{O}$ entendimento da internacionalização por meio da tradução de artigos para uma pretensa língua universal, no entanto, fortalece uma também pretensa elite científica que se separa daqueles que em seus próprios países não conhecem essa língua e atestam que não é universal; assim, se, de um lado, essa tradução amplia os que em outros países possam se valer da produção nacional, de outro, dificultam que os conterrâneos possam dela usufruir. Além disso, se para as ciências naturais e exatas, essa tradução quase não implica a perda de elementos culturais, o mesmo não ocorre com as ciências humanas, de maneira que para essa área, os que poderiam se beneficiar mais da ciência, mais são excluídos.

A resistência possível pode estar ligada a uma crescente democratização das formas de avaliação da produção e dos periódicos, forma pela qual se poderia ampliar a organização de um debate público sobre os interesses e o sentido da produção acadêmica nacional e internacional. Sem dúvida, todos os avaliadores se submetem ao mesmo processo de avaliação, revelando sua dimensão democrática, mas seria talvez o caso de nos perguntarmos (inspirando-nos em uma anedota atribuída a Bourdieu e citada no prefácio do livro de Dejours dedicado à reflexão sobre a avaliação no trabalho): como ampliar e democratizar a participação da comunidade acadêmica na formulação e avaliação das políticas de financiamento e de avaliação da produção científica? Nesse debate sobre a produção científica e sua publicação, dois elementos parecem essenciais: a reflexão a respeito do impacto da racionalidade econômica sobre a produção universitária e a problematização do estímulo à competição como forma predominante de organização do trabalho acadêmico.

\section{Referências}

Antunes, R. (2002). Os sentidos do trabalho: ensaio sobre a afirmação e negação do trabalho. São Paulo, SP: Boitempo.

Dejours, C. (2008). A avaliação do trabalho submetida à prova do real. São Paulo, SP: Blucher.

Domingues, I. (2014). O sistema de comunicação da ciência e o taylorismo acadêmico: questionamentos e alternativas. Estudos Avançados, 28(82), 225-250. doi: 10.1590/ S0103-40142014000300014.
Durand, J. P. (2003). A refundação do trabalho no fluxo tensionado. Tempo Social, 15(1), 139-158. doi: 10.1590/ S0103-20702003000100008.

Harvey, D. (2010). Condição pós-moderna: uma pesquisa sobre as origens da mudança cultural. São Paulo, SP: Loyola.

Horkheimer, M., \& Adorno, T. W. (1985). Dialética do esclarecimento. Rio de Janeiro, RJ: Jorge Zahar.

Marcuse, H. (1981). Eros e civilização: uma Interpretação Filosófica do Pensamento de Freud. Rio de Janeiro, RJ: Zahar. 
Oliveira, F. (1999). Privatização do público, destituição da fala e anulação da política: o totalitarismo neoliberal. In F. Oliveira, \& M. C. Paoli (Orgs.), Os sentidos da democracia: politicas do dissenso e hegemonia global (pp. 55-83). Petrópolis, RJ: Vozes.

Simmel, G. (2009). Psicologia do dinheiro e outros ensaios. Lisboa, Portugal: Texto \& Grafia.

Tassara, E. T. de O. (2013). Ética, conhecimento e poder. Leituras políticas de questões de método. Diálogos Possiveis, 12(1), 10-26. Recuperado de http://revistas. faculdadesocial.edu.br/index.php/dialogospossiveis/ article/view/78

Veblen, T. (1983). A teoria das classe ociosa. São Paulo, SP: Abril Cultural.

Weinberg, A. M. (1961). Impact of large-scale science on the United States: Big science is here to stay, but we have yet to make the hard financial and educational choices it imposes. Science, 134(3473), 161-164. Recuperado de http://www.sciencemag.org/content/134/3473/161.full. pdf 